\title{
A case of rectal Dieulafoy's ulcer and successful endoscopic band ligation
}

\author{
Yukako Yoshikumi MD PhD, Hirosato Mashima MD PhD, Junko Suzuki MD PhD, Yutaka Yamaji MD PhD, \\ Makoto Okamoto MD PhD, Keiji Ogura MD PhD, Takao Kawabe MD PhD, Masao Omata MD PhD
}

\begin{abstract}
Y Yoshikumi, H Mashima, J Suzuki, et al. A case of rectal Dieulafoy's ulcer and successful endoscopic band ligation. Can J Gastroenterol 2006;20(4):287-290.

Dieulafoy's ulcer is a rare cause of gastrointestinal bleeding. The lesion is usually located in the stomach, although it may occur anywhere in the gastrointestinal tract. A 44-year-old man was admitted to hospital due to cerebral infarction. On the 23rd day of hospitalization, he showed massive hematochezia. He underwent an urgent colonoscopy. There was a visible protuberant vessel without significant ulceration at the fundus of the rectum, consistent with a Dieulafoy's ulcer. It was treated by endoscopic hemoclipping. However, rebleeding occurred three times despite repeated hemoclipping. Finally, endoscopic band ligation was successfully performed to achieve permanent hemostasis. Endoscopic band ligation is an effective treatment for bleeding rectal Dieulafoy's ulcer.
\end{abstract}

\section{Un cas d'ulcère rectal de Dieulafoy et de ligature élastique endoscopique}

\begin{abstract}
L'ulcère de Dieulafoy est une rare cause de saignements gastrointestinaux. La lésion se trouve généralement dans l'estomac, mais elle peut se manifester n'importe où dans le tube digestif. Un homme de 44 ans a été hospitalisé en raison d'un infarctus cérébral. Le $23^{\mathrm{e}}$ jour de son hospitalisation, il a présenté une émission massive de selles sanglantes. Il a subi une coloscopie d'urgence. On constatait une protubérance des vaisseaux sans ulcération significative au fond du rectum, caractéristique d'un ulcère de Dieulafoy. On l'a traité à l'aide de pinces hémostatiques endoscopiques. Cependant, de nouveaux saignements se sont produits trois fois, malgré l'application répétée de pinces hémostatiques. Enfin une ligature élastique endoscopique a permis d'obtenir une hémostase permanente. La ligature élastique endoscopique est un traitement efficace de l'ulcère rectal hémorragique de Dieulafoy.
\end{abstract}

Key Words: Dieulafoy's ulcer; Endoscopic band ligation; Rectum

$\mathrm{D}^{\mathrm{i}}$ ieulafoy's ulcer is an uncommon lesion that usually presents with massive bleeding. This lesion is a dilated aberrant submucosal vessel which erodes the overlying epithelium in the absence of a primary ulcer (1). The typical endoscopic appearance is an abnormally large submucosal artery that protrudes through a solitary small mucosal defect. Histologically, it is defined as a thick-walled arterial vessel surrounded by a very shallow ulcer without the evidence of aneurysm formation, atherosclerosis, arteritis or inflammation. Dieulafoy's ulcers are usually found in the stomach, predominantly lying in the proximal one-third of the lesser curvature (2). Similar lesions have been reported throughout the rest of the gastrointestinal (GI) tract, including the esophagus, duodenum $(1,3-5)$, jejunum (6), colon (7-9) and rectum (10-33). To date, 30 cases of rectal Dieulafoy's ulcer have been reported in English medical literature. We report a case that was successfully treated with endoscopic band ligation after incomplete hemostasis with endoscopic hemoclipping.

\section{CASE PRESENTATION}

A 44-year-old man was admitted to hospital for a sudden disturbance of consciousness. He had a past medical history of hypertension, hyperlipidemia, diabetes mellitus and fatty liver. He had never previously experienced GI bleeding, colonic polyps or neoplasm. On admission, he was in a state of right hemiplegia, anarthria and consciousness disorder (Japan coma scale I: 2 to 3 ), as a result of a cerebral infarction due to the occlusion of the left internal carotid artery as demonstrated on computed tomography and magnetic resonance imaging. Other physical examinations were unremarkable. Blood examinations were normal except for leukocyte levels of $9.3 \times 10^{9} / \mathrm{L}$ (normal levels $4 \times 10^{9} / \mathrm{L}$ to $\left.9 \times 10^{9} / \mathrm{L}\right)$, glutamic-oxaloacetic transaminase levels of $79 \mathrm{U} / \mathrm{L}$ (normal levels $9 \mathrm{U} / \mathrm{L}$ to $38 \mathrm{U} / \mathrm{L}$ ), and glutamicpyruvic transaminase levels of $105 \mathrm{U} / \mathrm{L}$ (normal levels $4 \mathrm{U} / \mathrm{L}$ to $36 \mathrm{U} / \mathrm{L})$. He had a family history of hypertension, hyperlipidemia, diabetes mellitus, cerebral stroke, sudden death and heart disease. He was treated by fluid transfusion and anticoagulation therapy. His medication included $100 \mathrm{mg}$ of acetylsalicylic acid daily.

On the 23rd hospitalization day (HD), he showed massive hematochezia without abdominal pain. A digital rectal examination revealed a large amount of fresh blood and clots but no mass or fissure. His hemoglobin level dropped from $153 \mathrm{~g} / \mathrm{L}$ to $123 \mathrm{~g} / \mathrm{L}$ over $8 \mathrm{~h}$ and he therefore underwent urgent colonoscopy. A protuberant vessel was demonstrated at $5 \mathrm{~cm}$ above the anal verge without any significant ulceration at the fundus, consistent with a Dieulafoy's ulcer of the rectum (Figure 1A). It was endoscopically treated using two hemoclips (Figure 1B).

On the 27th HD, he again developed hematochezia. His hemoglobin level dropped to $75 \mathrm{~g} / \mathrm{L}$. Transfusion of four units of red blood cell (RBC) concentrates raised the hemoglobin level to $98 \mathrm{~g} / \mathrm{L}$. The patient underwent a second urgent colonoscopy. Active bleeding was not found throughout the colon. The protuberant vessel was still evident just next to the remaining hemoclips (Figure $1 \mathrm{C}$ ) and one more hemoclip was applied (Figure 1D). The patient also underwent esophagogastroduodenoscopy. Mild duodenitis was detected at the bulbus but it was not considered to be the source of massive bleeding.

Department of Gastroenterology, University of Tokyo, Bunkyo-ku, Tokyo

Correspondence and reprints: Dr Hirosato Mashima, 7-3-1 Hongo, Bunkyo-ku, Tokyo 113-8655. Telephone 81-3-3815-5411 ext 37194,

fax 81-3-5800-9738, e-mail hmashima1-tky@umin.ac.jp

Received for publication October 14, 2005. Accepted November 18, 2005 

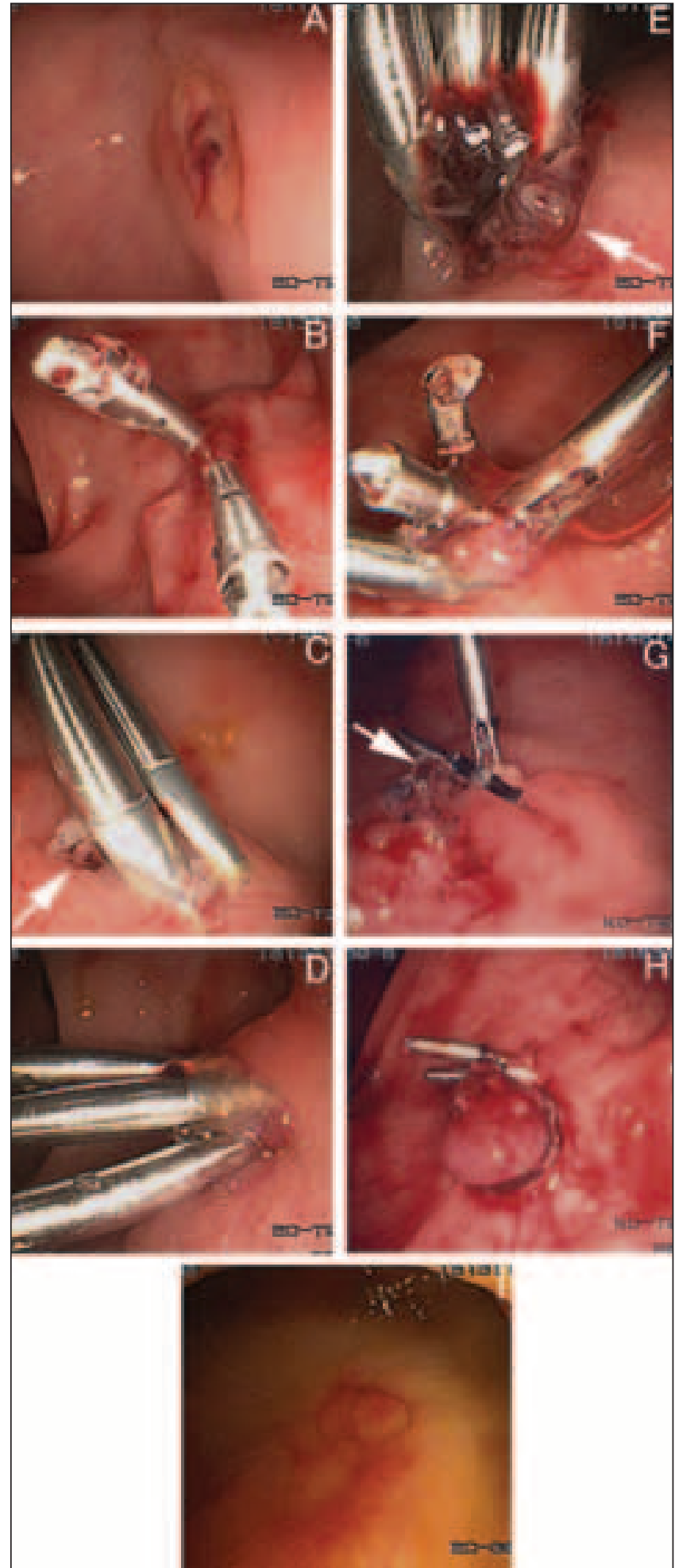

Figure 1) Series of endoscopic views of Dieulafoy's ulcer in the rectum. A (23rd hospitalization day [HD]): A protuberant vessel was surrounded by an almost normal mucosa; B (23rd HD): Endoscopic hemoclipping was performed; C (27th HD), E (31st HD): A protuberant vessel was evident beside the hemoclips (arrow); D (27th HD); F (31st HD): Additional hemoclipping was performed; G (35th HD): A small ulcer was found to have formed beside the remaining hemoclips. A small amount of blood oozed from the small vessel in the ulcer bed (arrow); H (35th HD): Endoscopic band ligation was performed; I (42nd HD): A red ulcer scar was detected in the rectum. There was no further bleeding
Bleeding recurred on the 31 st HD. His blood pressure fell to 75/50 mmHg. He became hemodynamically unstable and required transfusion with eight units of $\mathrm{RBC}$ concentrates. A technetium $99 \mathrm{~m}$-labelled RBC scintigraphy was performed to search for another source of the hemorrhage. It revealed an increased activity throughout the colon but it failed to identify the bleeding site. A third urgent colonoscopy was carried out. There was fresh blood and clots in the rectum and a protuberant vessel was visible again beside the hemoclips (Figure 1E). There was no other source of bleeding in the colon and two more hemoclips were applied to that lesion (Figure 1F).

On the 35th HD, he again developed massive hematochezia, amounting to $1100 \mathrm{~mL}$. His hemoglobin level dropped from $113 \mathrm{~g} / \mathrm{L}$ to $83 \mathrm{~g} / \mathrm{L}$. He was transfused with two units of RBC concentrates. He underwent a fourth urgent colonoscopy. Some of the hemoclips dropped out and there was a small ulcer beside the remaining hemoclips. A small vessel was visible in the ulcer bed and a small amount of blood was found to be oozing from it (Figure 1G). There was no blood in the proximal colon and no other lesions were detected in the distal colon with careful irrigation. A standard upper endoscope attached with a single band ligation device (PneumoActivated EVL device, Sumitomo Bakelite, Japan) was inserted into the rectum. A single elastic band was then applied on the vessel, leading to a complete cessation of the bleeding (Figure 1H). No complications occurred during the procedure.

A follow-up colonoscopy on the 42nd HD showed a red scar in the rectum (Figure 1I). There was no recurrence of bleeding during the one-year follow-up.

\section{DISCUSSION}

The causes of lower GI bleeding may be grouped into several categories: anatomy (diverticulosis), vasculature (angiodysplasia, ischemia and Dieulafoy's ulcer), inflammation (infection, radiation and idiopathy) and neoplasm. Diverticulosis accounts for approximately $30 \%$ to $50 \%$ and angiodysplasia accounts for approximately $15 \%$ to $30 \%$ of massive lower GI bleeding. In the evaluation of patients with severe lower GI bleeding, urgent colonoscopy has been proven to be superior to angiography, scintigraphy and surgery, demonstrating bleeding sites in up to $90 \%$ of cases (34-36). In addition, colonoscopy offers a chance for therapeutic intervention. The same therapeutic modalities used in upper endoscopy are available but the risk of complications is higher because of the thin wall of the colon in comparison to that of the stomach $(9,34)$.

Dieulafoy's ulcer of the rectum is an unusual cause of lower GI hemorrhage. In 1991, Franco et al (10) first reported a patient with Dieulafoy's ulcer of the rectum; since then, 30 additional cases have been reported, including the present case (Table 1). There may be a higher incidence in middle-aged men but this disease has been reported in all ages. The diagnosis of Dieulafoy's ulcer may be difficult because poor bowel preparation and stagnant blood contribute to the poor visualization. Improvement of general conditions with blood and/or fluid transfusion, pretreatment of colon with cleaning solution and careful irrigation are essential. The average number of colonoscopies to diagnose the lesions as Dieulafoy's ulcers was $1.7 \pm 0.9$ in 28 cases in literature. In two cases (case 5 and case 13 in Table 1), the source of hemorrhage could not be found with colonoscopy. Case 5 was diagnosed and treated surgically. Case 13 was treated with angiographic embolization, and subsequent 
TABLE 1

Characteristics of the reported rectal Dieulafoy's ulcers

\begin{tabular}{|c|c|c|c|c|c|c|c|c|}
\hline Reference & Year & Age (years) & Sex & Endoscopic finding $\mathrm{Di}$ & Diagnostic attempts & Treatment & Rebleeding & Retreatment \\
\hline Franko et al (10) & 1991 & 20 & M & Pulsatile bleeding & 1 & $E C$ (failure) + SL & - & \\
\hline Abdulian et al (11) & 1993 & 43 & $M$ & Protuberant vessel & 1 & Etl & $+(4$ days $)$ & $\mathrm{Etl}+\mathrm{SI}$ \\
\hline Tooson et al (12) & 1995 & 5 & $\mathrm{~F}$ & Protuberant vessel & 3 & $\mathrm{Epl}+\mathrm{HP}$ & - & \\
\hline Eguchi et al (14) & 1997 & 78 & $M$ & Failed to diagnosis & (1) & SL & - & \\
\hline Kalmann et al (15) & 1997 & 33 & $M$ & Protuberant adherent clot & 1 & $E p l+E C$ & $+(7$ days $)$ & $\mathrm{EC}$ \\
\hline & & 74 & M & Protuberant vessel & 2 & $\mathrm{Epl}+\mathrm{HP}$ & - & \\
\hline & & 77 & M & Adherent clot & 1 & $\mathrm{HP}$ & - & \\
\hline & & 67 & $M$ & Pulsatile bleeding & 1 & $\mathrm{Epl}+\mathrm{HP}$ & - & \\
\hline & & 7 & $M$ & Dieulafoy-like lesion & 1 & $\mathrm{Epl}+\mathrm{HP}$ & - & \\
\hline $\begin{array}{l}\text { Dobson and } \\
\text { Nicholson (18) }\end{array}$ & 1999 & 75 & $\mathrm{~F}$ & Failed to diagnosis & (1) & $A E$ & - & \\
\hline \multirow[t]{2}{*}{ Azimuddin et al (22) } & 2000 & 86 & $\mathrm{~F}$ & Protuberant vessel & 2 & SL & - & \\
\hline & & 81 & $\mathrm{~F}$ & Punctate mucosal defect & 4 & SE & - & \\
\hline \multirow[t]{2}{*}{ Kayali et al (23) } & 2000 & 77 & $\mathrm{~F}$ & Protuberant vessel & 2 & $\mathrm{Epl}+\mathrm{Etl}$ & - & \\
\hline & & 73 & $\mathrm{~F}$ & Protuberant vessel & 2 & $\mathrm{Epl}+\mathrm{Etl}$ & - & \\
\hline Rajendra et al (24) & 2000 & 78 & $M$ & Protuberant vessel & $\left(\mathrm{Er}_{\mathrm{p}}\right.$ & $(E p l+E C)($ failure $)+S L$ & - & \\
\hline Matsuoka et al (25) & 2000 & 54 & $\mathrm{~F}$ & Protuberant vessel & 3 & $E t l+E C$ & - & \\
\hline Enns (26) & 2001 & 72 & M & Pulsatile bleeding & 2 & $E p l+E C$ & - & \\
\hline Guy et al (27) & 2001 & 18 & $\mathrm{~F}$ & Pulsatile bleeding & 2 & $A E$ (failure) + ST & - & \\
\hline Jani (28) & 2001 & 60 & $M$ & Adherent clot & 1 & $\mathrm{Epl}$ & - & \\
\hline Nomura et al (29) & 2002 & 82 & M & Protuberant vessel & 1 & $\mathrm{CL}$ & - & \\
\hline Mizukami et al (30) & 2002 & 85 & $\mathrm{~F}$ & Protuberant vessel & 1 & $\mathrm{Epl}+\mathrm{BL}$ & - & \\
\hline
\end{tabular}

+ Yes; - No; AE Angiographic embolization; BL Band ligation; CL Hemoclipping; EC Electrocoagulation; Epl Adrenaline injection; EtI Ethanol injection; F Female; HP Heater probe thermocoagulation; M Male; SE Surgical excision; SI Sclerosant Injection; SL Surgical ligation; ST Surgical treatment

sigmoidoscopy confirmed the lesion. In recent studies, rectal Dieulafoy's ulcers were easily found, and the lesion could be determined in the first colonoscopy with careful irrigation. Although a histological diagnosis was not made in our case, the distinctive endoscopic features of the protuberant vessel without significant ulceration allowed us to diagnose it as a Dieulafoy's ulcer.

There is no consensus on the treatment of bleeding rectal Dieulafoy's ulcer and there are no randomized controlled studies comparing the different endoscopic therapies. Of the 30 reported cases, 21 patients were treated with endoscopic modalities alone, angioembolization was used in two cases and surgical treatment with or without other treatment was used in seven. Rebleeding occurred in five cases (17\%), in which the initial treatment was not uniform. One patient was treated with ethanol injection $(n=1)$, one with adrenaline injection $(n=3)$, one with adrenaline injection and electrocoagulation $(n=2)$, one with adrenaline injection and heater probe coagulation $(n=6)$, and one with angiographic embolization $(n=2)$. Recurrent bleeding was not reported after surgical treatment $(n=7$; five suture ligations, one excision and one unknown). Rebleeding tended to occur several days after the treatment except for case 30. Lee et al (33) reported a case of rebleeding $5 \mathrm{~h}$ after angiographic embolization but it was not clear whether complete hemostasis had been obtained by embolization.
In the present case, we first used endoscopic hemoclipping. Endoscopic treatment by hemoclip is recommended for rectal Dieulafoy's ulcer. It usually causes little injury to the colorectal wall, and complete hemostasis was obtained in all reported cases $(20,30,32)$. However, rebleeding from the lesion occurred three times in our patient. We paid careful attention to the optimal placement of the hemoclips. Rebleeding may have been due to the fragility of the wall, sclerotic change of the vessel or the application of anticoagulation therapy. In the first urgent colonoscopy, we tried endoscopic clipping with six hemoclips, in which only two hemoclips firmly grasped the lesion. This middleaged man had several risk factors and a family history of atherosclerosis. Acetylsalicylic acid was continued up to the 27th HD, because iodine-123-labelled $\mathrm{N}$-isopropyl-p-iodoamphetamine brain single photon emission computed tomography revealed moderate to severe hypoperfusion in the larger area of the left internal carotid artery territory than in the infarcted area.

Finally, endoscopic band ligation was successfully performed. Band ligation has been proven to be safe and effective in the treatment of bleeding esophageal varices (37-39) with fewer complications compared with sclerotherapy. Recently, this modality has been used effectively in the endoscopic treatment of bleeding rectal varices (40) and nonvariceal upper GI bleeding (41). Endoscopic band ligation with adrenaline injection was reported 
to be successful for the recurrent bleeding after angioembolization (33) as well as for naïve cases of rectal Dieulafoy's ulcer $(30,32)$. In our patient, endoscopic band ligation was applied for recurrent bleeding from Dieulafoy's ulcer without an adrenaline injection. The lesion was located $5 \mathrm{~cm}$ from the anal verge, on the anal side of the peritoneal reflection, so we decided that a perforation due to the endoscopic procedures was unlikely to occur. Recurrent bleeding has not been reported after surgical treatment and therefore we took surgery into consideration in cases of rebleeding rectal Dieulafoy's ulcer. Endoscopic band ligation is simple, readily available, relatively inexpensive and may be highly effective in patients with coagulopathies or hemorrhages (42). We used a standard upper endoscope to perform band ligation in the present case. However, the banding apparatus fitted on colonoscopes with smaller

\section{REFERENCES}

1. Lee YT, Walmsley RS, Leong RW, Sung JJ. Dieulafoy's lesion. Gastrointest Endosc 2003;58:236-43.

2. Veldhuyzen van Zanten SJ, Bartelsman JF, Schipper ME, Tytgat GN. Recurrent massive haematemesis from Dieulafoy vascular malformations: Review of 101 cases. Gut 1986;27:213-22.

3. Pollack R, Lipsky H, Goldberg RI. Duodenal Dieulafoy's lesion. Gastrointest Endosc 1993;39:820-22.

4. Anireddy D, Timberlake G, Seibert D. Dieulafoy's lesion of the esophagus. Gastrointest Endosc 1993;39:604.

5. Choudari CP, Palmer KR. Dieulafoy's lesion of the duodenum; successful endoscopic therapy. Endoscopy 1993;25:371.

6. Matuchansky C, Babin P, Abadie JC, Payen J, Gasquet C, Barbier J. Jejunal bleeding from a solitary large submucosal artery: Report of two cases. Gastroenterology 1978;75:110-3.

7. Barbier P, Luder P, Triller J, Ruchti C, Hassler H, Stafford A. Colonic hemorrhage from a solitary minute ulcer: Report of three cases. Gastroenterology 1985;88:1065-8.

8. Richards WO, Grove-Mahoney D, Williams LF. Hemorrhage from a Dieulafoy-type ulcer in the colon: A new cause of lower gastrointestinal bleeding. Am Surg 1988;54:121-4.

9. Dy NM, Gostout CJ, Balm RK. Bleeding from the endoscopicallyidentified Dieulafoy lesion of the proximal small intestine and colon. Am J Gastroenterol 1995;90:108-11.

10. Franko E, Chardavoyne R, Wise L. Massive rectal bleeding from a Dieulafoy's type ulcer of the rectum: A review of this unusual disease. Am J Gastroenterol 1991;86:1545-7.

11. Abdulian JD, Santro MJ, Chen YK, Collen MJ. Dieulafoy-like lesion of the rectum presenting with exsanguinating hemorrhage: Successful endoscopic sclerotherapy. Am J Gastroenterol 1993;88:1939-41.

12. Tooson JD, Marsano LS, Gates LK Jr. Pediatric rectal Dieulafoy's lesion. Am J Gastroenterol 1995;90:2232-3.

13. Yeoh KJ, Kang JY. Dieulafoy's lesion in rectum. Gastrointest Endosc 1996;43:614-16.

14. Eguchi S, Maeda J, Taguchi H, Kanematusu T. Massive gastrointestinal bleeding from a Dieulafoy-like lesion of the rectum. Clin Gastroenterol 1997;24:262-3.

15. Kalman DR, Banner BF, Barnard GF. Rectal Dieulafoy's or angiodysplasia? Gastrointest Endosc 1997;46:91-2.

16. Abdelmalek MF, Pockaj BA, Leighton JA. Rectal bleeding from a mucous fistula secondary to a Dieulafoy's lesion. J Clin Gastroenterol 1997;24:259-61

17. Meister TE, Varilek GW, Marsano LS. Endoscopic management of rectal Dieulafoy-like lesions: A case series and review of literature. Gastrointest Endosc 1998;48:302-5.

18. Dobson CC, Nicholson AA. Treatment of rectal hemorrhage by coil embolization. Cardiovasc Intervent Radiol 1999;22:143-6.

19. Amaro R, Petruff CA, Rogers AI. Rectal Dieulafoy's lesion: Report of a case and review of the literature. Dis Colon Rectum 1999;42:1339-41.

20. Nozoe T, Kitamura M, Matsumata T, Sugimachi K. Dieulafoy-like lesions of colon and rectum in patients with chronic renal failure on long-term hemodialysis. Hepatogastroenterology 1999;46:3121-3

21. Yarze JC, Schupp SL, Friz HP, Lusignan DN. Hemorrhage related to an anal Dieulafoy-like lesion. Am J Gastroenterol 2000;95:1593-4. diameters such as the Olympus PCF series (Japan). Small bleeding lesions were occasionally missed while we attached the apparatus. In cases using those scopes, band ligation can be performed without changing the scopes. The ligation apparatus can be fixed on the tip of the endoscope more quickly and easily than conventional hemoclips. This modality may have a potential to be used as a first-line therapy. Band ligation completely controlled the bleeding with no evidence of recurrence in all four patients, including our patient $(30,32,33)$. The mechanism of hemostasis by mechanical strangulation of the vessel makes this technique very suitable in patients with coagulopathies or using anticoagulant drugs.

In conclusion, endoscopic band ligation was found to be an effective treatment for bleeding rectal Dieulafoy's ulcer even after other therapeutic modalities had failed.

22. Azimuddin K, Stasik JJ, Rosen L, Riether RD, Khubchandani IT. Dieulafoy's lesion of the anal canal: A new clinical entity. Report of two cases. Dis Colon Rectum 2000;43:423-6.

23. Kayali Z, Sangchantr W, Matsumoto B. Lower gastrointestinal bleeding secondary to Dieulafoy-like lesion of the rectum. J Clin Gastroenterol 2000;30:328-30.

24. Rajendra T, Chung YF, Ong HS. Rectal Dieulafoy's lesion: Cause of massive lower gastrointestinal tract hemorrhage. Aust NZJ Surg 2000;70:746-7.

25. Matsuoka J, Taniai K, Kojima K, et al. A case of rectal Dieulafoy's ulcer and successful endoscopic sclerotherapy. Acta Med Okayama 2000;54:281-3.

26. Enns R. Dieulafoy's lesion of the rectum: A rare cause of lower gastrointestinal bleeding. Can J Gastoenterol 2001;15:541-5.

27. Guy RJ, Ang ES, Tan KC, Tsang CB. Massive bleeding from a Dieulafoy-like lesion of rectum in a burns patient. Burns 2001;27:767-9.

28. Jani PG. Dieulafoy's lesion: Case report. East Afr Med J 2001;78:109-10.

29. Nomura S, Kawahara K, Yamasaki K, Nakanishi Y, Kaminishi M. Massive rectal bleeding from a Dieulafoy lesion in the rectum: Successful endoscopic clipping. Endoscopy 2002;34:237.

30. Mizukami Y, Akahoshi K, Kondoh N, Harada N, Nawata H. Endoscopic band ligation for rectal Dieulafoy's lesion: Serial endoscopic images. Endoscopy 2002;34:1032.

31. Abe T, Okada N, Akamatsu H, et al. Successful endoscopic hemostasis of rectal Dieulafoy's ulcer by clipping: Aging may be a factor. Dig Endosc 2003; $15: 64-8$

32. Fujimaru T, Akahoshi K, Matsuzaka H, Sumita Y, Kubokawa M. Bleeding rectal Dieulafoy's lesion. Gastrointest Endosc 2003;57:922.

33. Lee CS, Widjaja D, Siegel M, Bodenheimer HC Jr. Endoscopic band ligation of a rectal Dieulafoy's lesion. J Clin Gastroenterol 2004:38:828-30.

34. Jensen DM, Machicado GA. Advanced therapeutic endoscopy. New York: Raven, 1994:201-8.

35. Jensen DM, Machicado GA. Diagnosis and treatment of severe hematochezia: The role of urgent colonoscopy after purge. Gastroenterology 1988;95:1569-74.

36. Richter JM, Christensen MR, Kaplan LM, Nishioka NS. Effectiveness of current technology in the diagnosis and management of lower gastrointestinal hemorrhage. Gastrointest Endosc 1995;41:93-8.

37. Laine L, El-Newihi HM, Migikovsky B, Sloane R, Garcia F. Endoscopic ligation compared with sclerotherapy for the treatment of bleeding esophageal varices. Ann Intern Med 1993;119:1-7.

38. Stiegmann GV, Goff JS, Michaletz-Onody PA, et al. Endoscopic sclerotherapy as compared with endoscopic ligation for bleeding esophageal varices. N Engl J Med 1992;326:1527-32.

39. Gimson AE, Ramage JK, Panos MZ, et al. Randomized trial of variceal banding ligation versus injection sclerotherapy for bleeding esophageal varices. Lancet 1993;342:391-4.

40. Levine J, Tahiri A, Banerjee S. Endoscopic ligation of bleeding rectal varices. Gastrointest Endosc 1993;39:188-9.

41. Tseng C, Burke S, Connors P, Green R, Carr-Locke DL. Endoscopic band ligation for treatment of non-variceal upper gastrointestinal bleeding. Endoscopy 1991;23:297-8.

42. Nikolaidis N, Zezos P, Giouleme O, et al. Endoscopic band ligation of Dieulafoy-like lesions in the upper gastrointestinal tract. Endoscopy 2001;33:754-60. 


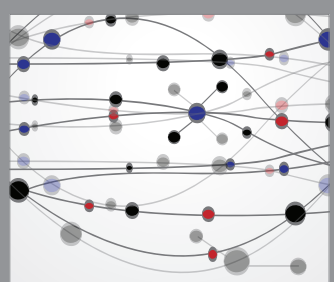

The Scientific World Journal
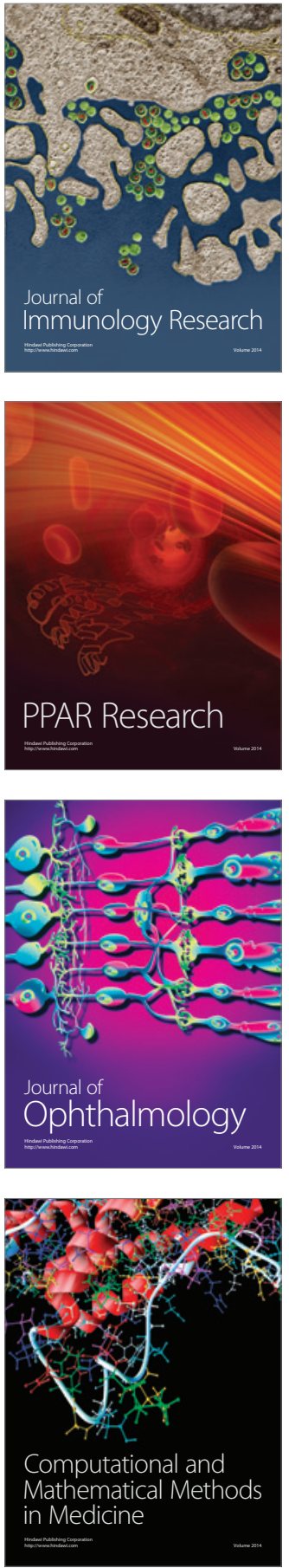

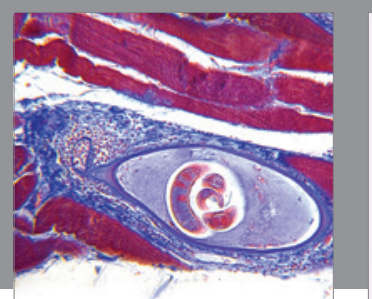

Gastroenterology Research and Practice

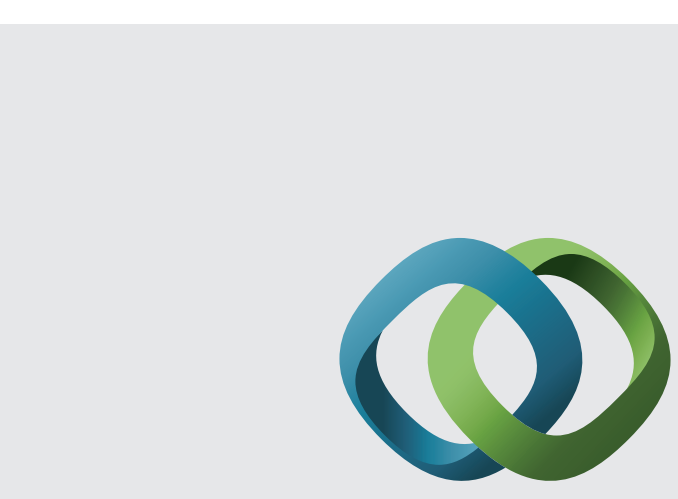

\section{Hindawi}

Submit your manuscripts at

http://www.hindawi.com
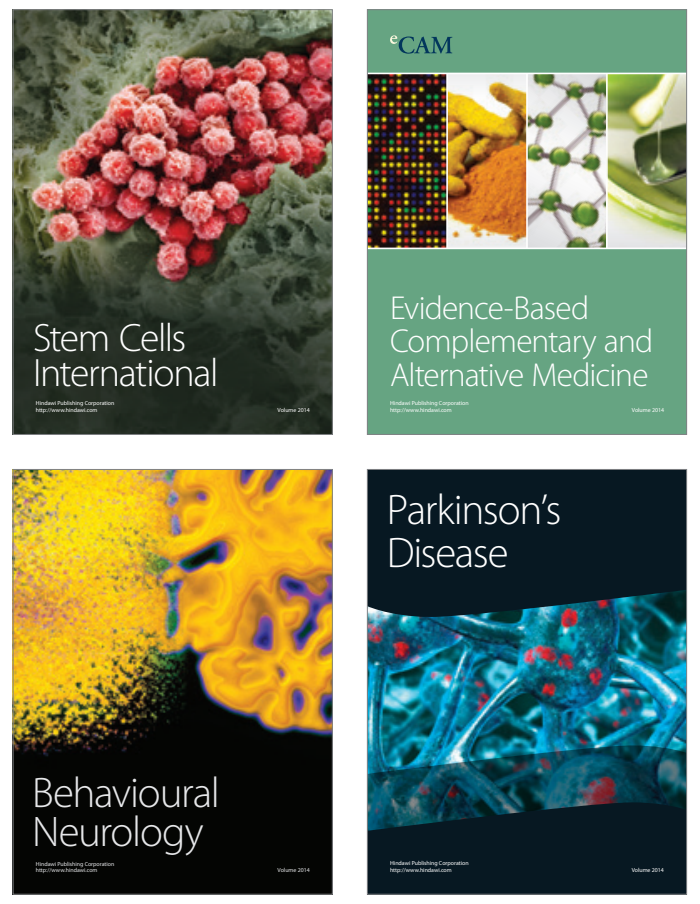
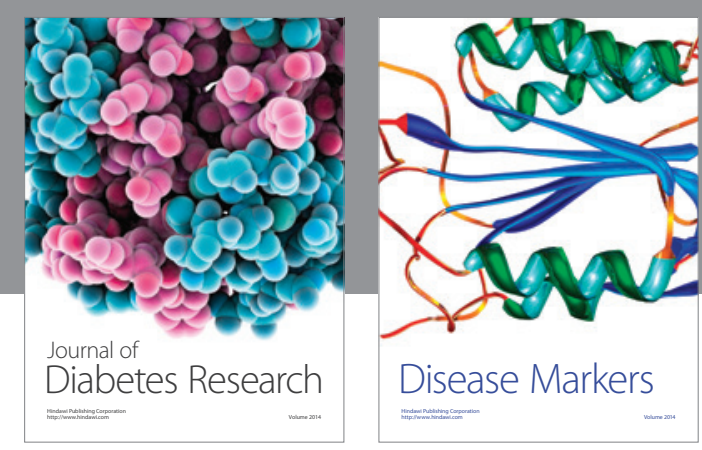

Disease Markers
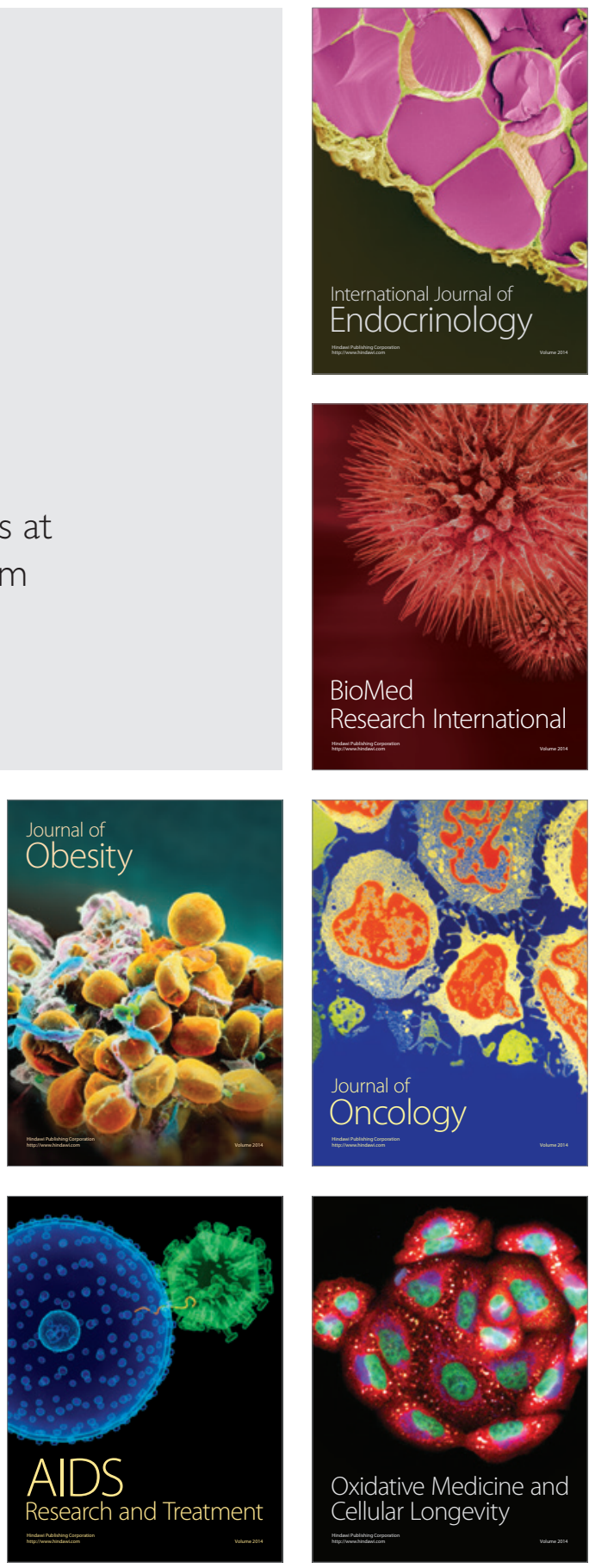